\title{
Fusarium co-infection in a patient of tubercular meningitis
}

\author{
Ravinder Kaur, Pragyan S. Panda
}

\begin{abstract}
Fusarium is a common soil fungus and it can cause serious illness in humans. Fusariosis is usually more invasive and disseminated in immune compromised individuals. We report a rare case of concomitant Fusarium meningitis in a patient with tubercular meningitis.
\end{abstract}

Key words: Co-infection, Fusarium, tubercular meningitis

\section{INTRODUCTION}

Fusarium species are important plant pathogens that occasionally cause infection in humans. Fusarium species can cause superficial infections (superficial keratitis, onychomycosis, allergic sinusitis) in immunocompetent individuals. ${ }^{[1]}$ However, infection in the immunocompromised population is typically invasive and disseminated..$^{[1,2]}$ We report a case of concomitant Fusarium meningitis in a patient with tubercular meningitis (TBM).

\section{CASE REPORT}

A 14-year-old $34 \mathrm{~kg}$ girl presented to us with the complaints of a prolonged febrile illness and 1 day history of repeated generalised tonic-clonic seizures (GTCS). The patient had a history of low-grade fever (without chills

Department of Microbiology, Maulana Azad Medical College and Associated Hospitals, Bahadur Shah Zafar Marg,

New Delhi, India

\section{Address for correspondence:}

Dr. Ravinder Kaur, Department of Microbiology,

Maulana Azad Medical College and Associated Hospitals,

Bahadur Shah Zafar Marg, New Delhi - 110 002, India.

E-mail: drkaur@hotmail.com

\begin{tabular}{|l|l|}
\hline \multicolumn{2}{|c|}{ Access this article online } \\
\hline Quick Response Code: & Website: \\
\hline & www.jnaccjournal.org \\
\cline { 2 - 2 } & \\
\hline
\end{tabular}

and rigors) for 9 months and 4 months ago, following a persistent headache she was diagnosed to have TBM on the basis of cerebrospinal fluid (CSF) examination. The patient was receiving standard doses of isoniazid, rifampin, pyrazinamide and pyridoxine for the past 4 months. There was no history of trauma, previous seizures, skin lesions or family history of tuberculosis or hypertension. About 15 days before hospitalisation, she had a persistent severe headache for which analgesics and tablet dexamethasone (4 mg thrice a day) was started. After that, her headache decreased in severity but 7 days before admission the severity of a headache again increased. Before presenting to us, she also had repeated GTCS since 1 day. On presentation, her blood pressure was 150/108 $\mathrm{mmHg}$ and her other systemic examination was within normal limits. The patient was managed symptomatically with antiepileptic medications.

Apart from haemoglobin level of $10.4 \mathrm{~g} / \mathrm{dl}$ and white blood cell count of 18,390 cells $/ \mathrm{mm}^{3}$ (63\% neutrophils and $30 \%$ lymphocytes), her other haematological investigations and non-contrast computed tomography scan of the head were normal. The serological markers for hepatitis and HIV were non-reactive. On the basis of clinical presentation and available test reports, CSF examination was done, and no further ophthalmological

This is an open access article distributed under the terms of the Creative Commons Attribution-NonCommercial-ShareAlike 3.0 License, which allows others to remix, tweak, and build upon the work non-commercially, as long as the author is credited and the new creations are licensed under the identical terms.

For reprints contact: reprints@medknow.com

How to cite this article: Kaur R, Panda PS. Fusarium co-infection in a patient of tubercular meningitis. J Neuroanaesthesiol Crit Care 2016;3:249-51. 
examination or tests for detection of haematological malignancy or brain abscess were attempted.

The CSF examination of the patient revealed total leucocyte count, protein and sugar levels to be 306 cells $/ \mathrm{mm}^{3}$ (lymphocytes $60 \%$ and neutrophills $40 \%$ ), $210 \mathrm{mg} / \mathrm{dl}$ and $106 \mathrm{mg} / \mathrm{dl}$, respectively. On direct microscopy of CSF, hyaline, narrow, septate and branching fungal hyphae were seen. The sample was inoculated onto Sabouraud's Dextrose agar with and without cycloheximide and was incubated both at $25^{\circ} \mathrm{C}$ and $37^{\circ} \mathrm{C}$. The cultures yielded colonies that were cottony white to pink with a floccose aerial mycelium. The lactophenol cotton blue mount was prepared which when examined under $\times 10$ followed by $\times 40$ objective of the microscope revealed, one-/two-celled, oval microconidia, $8-9 \mathrm{~mm} \times 2-3 \mathrm{~mm}$ in size, grouped in chains and produced from simple lateral phialides [Figure 1]. The organism was identified to be Fusarium spp. The blood culture did not yield any fungus, but the repeat CSF examination (before starting antifungal therapy) again revealed Fusarium spp. The patient was treated with amphotericin B (intravenous) (loading dose of $0.75 \mathrm{mg} / \mathrm{kg}$ followed by $1 \mathrm{mg} / \mathrm{kg})^{[3]}$ for 14 days along with the on-going antitubercular medications. The patient improved and the CSF examination following 14 days of antifungal therapy yielded no fungal growth. The patient was discharged subsequently after 25 days of hospital admission with on-going antitubercular and antiepileptic medications.

\section{DISCUSSION}

The different fungi implicated in causing meningitis are Cryptococcus neoformans, Coccidioides immitis, Candida sp., Histoplasma capsulatum, Aspergillus sp., Sporothrix schenckii, and Blastomyces dermatitidis. ${ }^{[4]}$ The most common route of entry of fungi to the human

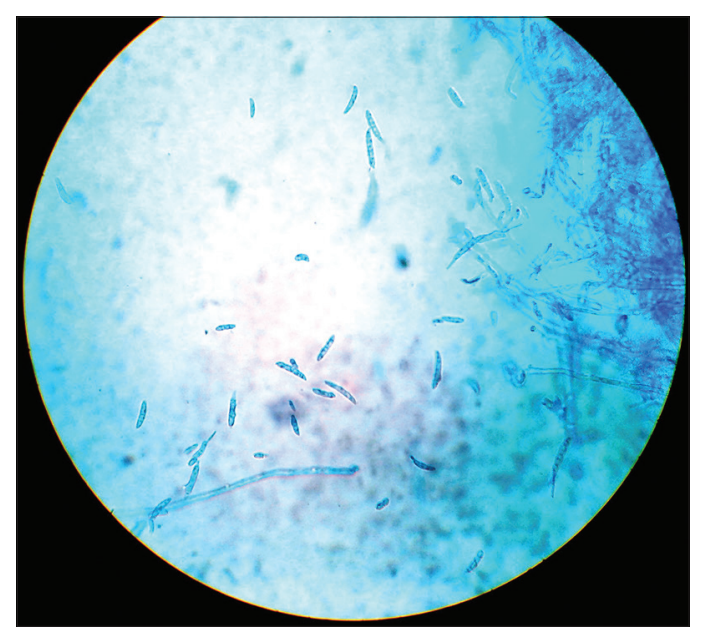

Figure 1: Lactophenol cotton blue mount showing macro and micro conidia of Fusarium body is through inhalation of airborne fungal spores. The initial pulmonary infection may be asymptomatic and is often self-limited. However, a dormant localised pulmonary fungal infection can remain, and an immunocompromised status may allow the fungus to reactivate and disseminate to the central nervous system (CNS). Organ transplant recipients, patients on chemotherapy, patients with immunocompromised state or haematological malignancies have increased the risk for fungal infection of CNS.

The skin and respiratory tract are the primary portals of entry of Fusarium species into the human body. In humans, Fusarium species cause superficial, locally invasive and disseminated infections. The clinical form of fusariosis depends largely on the immune status of the host, and the severe form of infection is usually encountered in immune compromised patients. ${ }^{[1]}$ Fusarium brain abscess and meningitis has been reported in a patient with chronic infectious mononucleousis syndrome and immunodeficiency where the patient died despite abscess aspiration and treatment with amphotericin B. ${ }^{[2]}$ However, another patient of the chronic granulomatous disease had long standing chronic disseminated Fusarium infection with multiple soft tissue abscesses and was successfully treated with antibiotic and antifungal therapy. ${ }^{[5]}$ However, Fusarium infection in a patient with TBM has rarely been reported. Fusarium is highly resistant to conventional antifungal drugs and amphotericin $B$ and voriconazole are the two antifungal agents that are used with some success to treat Fusarium infection in human.

In our case, the patient had TBM with concomitant Fusarium meningitis causing persistence of meningitis in spite of anti-tubercular therapy. She probably had a state of compromised immune status due to on-going steroid therapy and poor nutritional status which lead to the Fusarium infection. CNS vascular invasion by Fusarium has been noted before other organ system involvement in disseminated Fusarium infection..$^{[2]}$ This might explain the CNS invasion by Fusarium in our patient. In this report, we want to emphasise the fact that due to on-going steroid therapy, patients of TBM can have a compromised immune status, leading to opportunistic fungal infection.

Fungal infection of CNS many a times becomes a diagnostic and therapeutic challenge. In patients with TBM, that is unresponsive to anti-tubercular therapy a thorough microbiological evaluation, might detect an unlikely fungal pathogen leading to initiation of timely management.

\section{Financial support and sponsorship Nil.}




\section{Conflicts of interest}

There are no conflicts of interest.

\section{REFERENCES}

1. Nucci M, Anaissie E. Fusarium infections in immunocompromised patients. Clin Microbiol Rev 2007;20:695-704.

2. Steinberg GK, Britt RH, Enzmann DR, Finlay JL, Arvin AM. Fusarium brain abscess. Case report. J Neurosurg 1983;58:598-601.
3. Richardson MD, Jones BL. Therapeutic guidelines in systemic fungal infection. $3^{\text {rd }}$ ed. London. Current Medical Literature 2003. p. 25-43.

4. Koroshetz WJ, Swartz MN. Chronic and Recurrent Meningitis. In: Fauci AS, Kasper DL, Longo DL, Braunwald E, Hauser SL, Jameson JL, et al. editors. Harrison's Principles of Internal Medicine. 17th ed. New York. The McGraw-Hill Companies, Inc.; 2008. p. 2641-6.

5. Mansoory D, Roozbahany NA, Mazinany H, Samimagam A. Chronic Fusarium infection in an adult patient with undiagnosed chronic granulomatous disease. Clin Infect Dis 2003 1;37:e107-8. 